\title{
Оценка возможности использования карты береговых линий GSHHG для автономной оптической навигации космических аппаратов
}

\author{
Е.А. Балдина ${ }^{1}$ Р.В. Бессонов ${ }^{2}$, В.А.Гришин ${ }^{2}$, Б.С. Жуков ${ }^{2}$ Е.Г. Харьковец ${ }^{1}$ \\ ${ }^{1}$ МГУ им. М.В. Ломоносова, Москва, 119991, Россия \\ E-mail: baldinaea@yandex.ru \\ ${ }^{2}$ Институт космических исследований РАН, Москва, 117997, Россия \\ E-mail: besson777@rambler.ru
}

\begin{abstract}
С целью использования при разработке аппаратуры и алгоритмов космической автономной оптической навигации проведена оценка временной изменчивости пространственного положения береговой линии Европы и северной Африки и точности ее изображения на карте GSHHG (Global Self-consistent, Hierarchical, High-resolution Geography Database). На основе анализа литературных источников, посвященных береговой зоне Мирового океана и ее особенностям на выбранной для исследования территории, создана карта потенциальной долговременной изменчивости береговой линии. Оценка точности изображения береговой линии GSHHG проведена путем сравнения с изображением на современных космических снимках, полученных в 2013-2015 гг. системой OLI/Landsat-8. Результаты работы представлены в виде карты, характеризующей степень соответствия береговой линии GSHHG и ее положения, определенного по снимкам и принятого за истинное. Проведенная работа позволила количественно оценить степень пригодности карты GSHHG для решения навигационных задач. Выявлено, что изменчивыми и непригодными для навигации являются около $8 \%$ обследованной береговой линии, а неизменчивыми и потенциально пригодными - 67\%, оставшиеся 25\% пригодны условно. При этом лишь 9\% береговой линии, изображенной на карте GSHHG, отклоняются от положения, принятого за истинное, не более, чем на 100 м; 34\% - не более 200 м и 40\% - не более 500 м. Сделан вывод о необходимости критической ревизии базы данных GSHHG для того, чтобы полностью использовать потенциал космической оптической навигации по неизменным участкам береговой линии.
\end{abstract}

Ключевые слова: изменчивость береговой линии, точность карты GSHHG, автономная оптическая навигация

Одобрена к печати: 28.03 .2016

DOI: $10.21046 / 2070-7401-2016-13-3-217-228$

\section{Введение}

Автономная оптическая навигация может служить дополнительным средством, повышающим точность навигации на орбитах вокруг Земли, что может быть особенно важным в случае невозможности использования спутниковых навигационных систем ГЛОНАCC/GPS. При межпланетных перелетах и на орбитах вокруг других тел Солнечной системы автономная оптическая навигация может быть основным источником навигационной информации. Этот метод навигации основан на определении орбиты КА путем бортовой обработки в реальном времени изображений Земли или других тел Солнечной системы. Отработку методов автономной оптической навигации естественно проводить на орбитах вокруг Земли.

Начальное относительно грубое определение положения КА может проводиться по изображениям горизонта (Жуков и др., 2015), а затем уточняться по ориентирам на поверхности (Гришин, 2014). При наблюдении Земли из космоса наиболее надежно распознается береговая линия, которая имеет высокий контраст в ближнем ИК диапазоне (0,8-0,9 мкм) и на многих участках относительно устойчива во времени. Сходная задача решается при наземной географической привязке космических изображений (Егошкин и др., 2009). 
Задача автономной оптической навигации КА требует создания навигационных камер со специализированным программно-алгоритмическим обеспечением, в которых в условиях жестких ограничений вычислительных ресурсов в реальном времени должен проводиться весь цикл обработки получаемых изображений, включая предварительную обработку (коррекцию), фильтрацию облачности, распознавание горизонта и береговой линии, определение по ним мгновенного положения КА, накопление измерений и определение орбиты с использованием баллистической фильтрации. Для этого навигационные камеры должны работать в комплексе со звездными приборами измерения ориентации КА, успешно функционирующими в космосе уже на протяжении многих лет. В качестве примера последних можно привести звездные датчики семейства БОКЗ производства ИКИ РАН (Аванесов и др., 2015).

Точность навигационных измерений повышается как при улучшении пространственного разрешения камеры вследствие повышения точности измерения координат ориентиров, так и при расширении поля зрения камеры из-за увеличения угла засечки и повышения вероятности наблюдения надежно географически привязанных участков береговой линии в безоблачных условиях. Поскольку высокое пространственное разрешение и большое поле зрения камеры не могут быть обеспечены одновременно, необходимо искать компромисс между ними. Поэтому важной задачей является оценка точности существующих карт береговой линии, поскольку нет необходимости выбирать разрешение навигационной камеры лучше, чем точность имеющихся карт.

Задачей настоящей работы являлась оценка точности наиболее широко используемой в настоящее время базы данных береговых линий GSHHG и определение наиболее устойчивых и точно изображенных участков береговых линий, которые целесообразно использовать для космической навигации.

На первом этапе исследования проводились на примере береговой линии Европы и северной Африки между параллелями $30^{\circ}$ и $60^{\circ}$ с.ш.

\section{Используемые материалы}

\section{Карты береговой линии GSHHG}

GSHHG - Global Self-consistent, Hierarchical, High-resolution Geography Database общедоступная картографическая база данных, которая включает карты береговой линии нескольких взаимно согласованных уровней детальности (http://www.soest. hawaii.edu/pwessel/gshhg). GSHHG была создна П. Весселем и У. Смитом (Wessel, Smith, 1996) на основе находящихся в открытом доступе векторных баз данных по береговой линии.

На протяжении более двух десятилетий GSHHG широко используется в разнообразных исследованиях и практической деятельности. К числу наиболее ранних при- 
менений относится проект ее использования для координатной привязки изображений радиометра AVHRR/NOAA (Spaulding, 1990) с пространственным разрешением 1 км.

База данных постоянно совершенствуется и представлена разработчиками на портале открытого доступа. Полная база данных включает 188628 полигонов, содержащих координаты 10222509 точек береговой линии. Системой координат GSHHG является WGS84, береговая линия нанесена по среднему уровню прилива. Данные хранятся в пяти разных уровнях детальности: “полный” (full resolution - “f”), “высокий” (high resolution - “h”), “средний” (intermediate resolution - “i”), “низкий” (low resolution - “l”), “обзорный” (“грубый”) (crude resolution - “c”).

База данных рекомендована к использованию в масштабах от 1:250 000 для уровня “f” до 1:120 000000 для уровня “c”. Точность карты в масштабе 1:250 000 характеризуется круговой вероятностной ошибкой в 500 м при 90 \% уровне обеспеченности (2 мм на карте в этом масштабе). Следовательно, при использовании более мелких масштабов, точность положения береговой линии будет ниже.

При использовании GSHHG для оптических систем навигации неизбежно встает вопрос о соответствии этой базы картографических данных реальному современному положению береговой линии. В качестве современного положения береговой линии мы предлагаем принять ее изображение, определяемое по снимкам OLI/Landsat-8.

\section{Снимки с ИСЗ серии Landsat}

Съемочная система OLI на ИС3 Landsat-8 выполняет съемку Земли с апреля 2013 г. в видимом и ближнем инфракрасном (БИК) диапазонах с пространственным разрешением снимков 30 м и в тепловом инфракрасном с разрешением 100 м. Ввиду того, что съемка с ИС3 Landsat-8 является продолжением 43-х летней глобальной съемки Земли со спутников этой серии, появляется возможность использовать не только последние снимки, но и те, что были получены 20-30 лет назад, что обеспечивает выявление изменений. Существенно то, что за долгие годы функционирования системы Landsat были отработаны алгоритмы калибровки и геометрической коррекции получаемых данных, в результате чего обеспечивается полная пространственная сопоставимость разновременных снимков. Ошибка пространственной привязки данных OLI/Landsat-8 оценивается для данных видимого и БИК диапазонов в 12 м (круговая вероятностная ошибка 90 \% обеспеченности). Данные предоставляются в системе координат WGS 84, с проведенной коррекцией за рельеф. В 12 метров оценивается и точность взаимной привязки разновременных снимков Landsat-8 (USGS. Landsat 8..., 2015).

Оценка качества пространственной привязки разновременных снимков Landsat показывает, что их использование обеспечивает выполнение картографических работ с точностью 1:100 000 масштаба. В то же время, карта GSHHG, по заявлению ее составителей, обеспечивает точность положения контуров в масштабе не крупнее 1:250 000, 


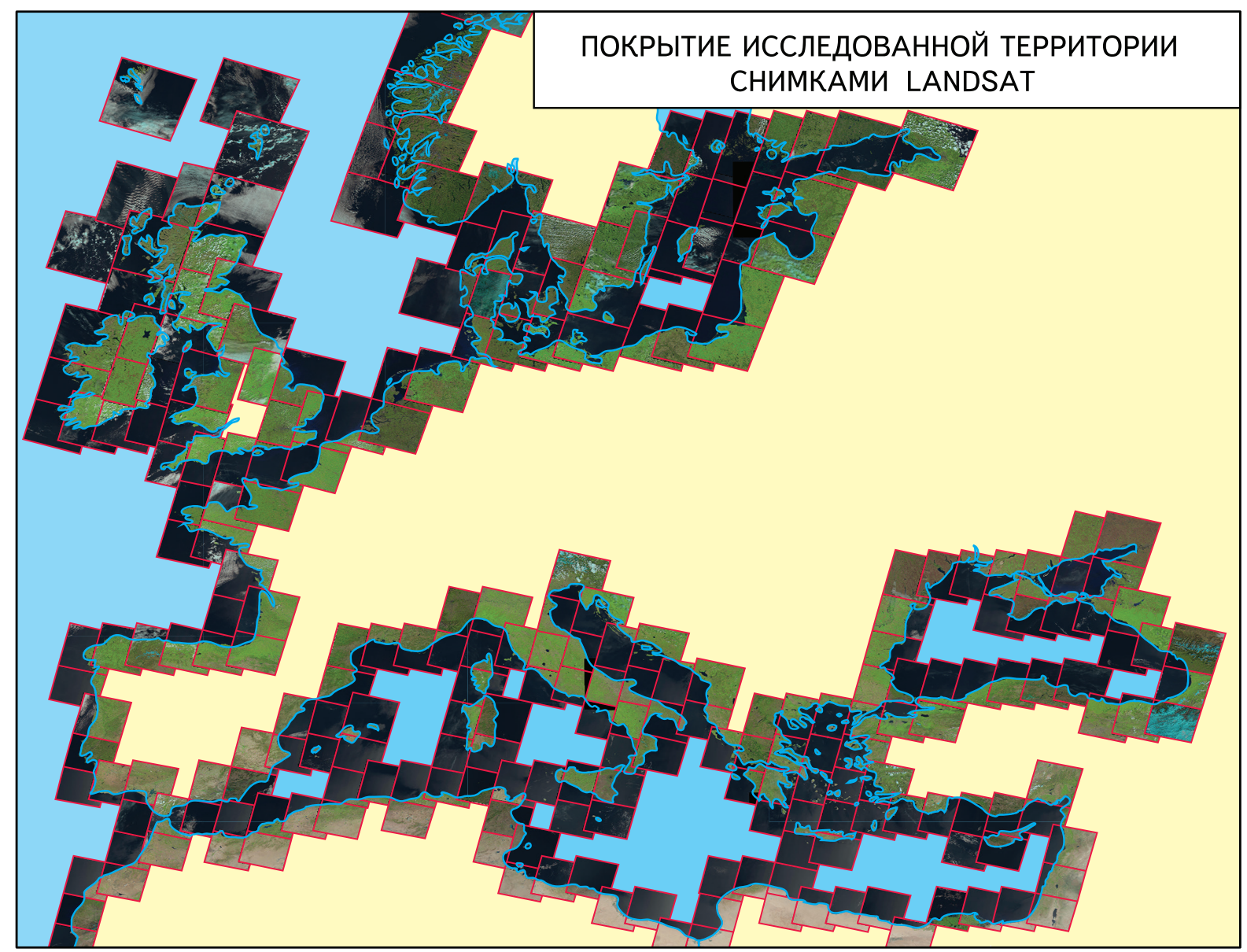

Pис. 1. Покрытие исследованной территории снимками Landsat-8

что позволяет при оценке точности пространственного положения и качества изображения береговой линии этой карты принять данные Landsat в качестве «истинных».

Для выполнения работы использовано более 300 снимков Landsat-8, находящихся в открытом доступе. Снимки синтезированы с натуральной цветопередачей, имеют размер пиксела 30 м и покрывают весь регион исследования (рис. 1). На некоторые территории, например, на илистые (ваттовые) берега, участки дельт, дополнительно было использовано по 2-3 разносезонных снимка Landsat-8, что позволяло проверить изменчивость положения береговой линии в разные сезоны съемки.

Литературные и картографические источники по изменчивости морских берегов

Свойства морских берегов и их изменчивость являются предметом геоморфологии морских берегов - науки, имеющей более чем 100-летний период развития и обширную библиографию. При создании карты потенциальной изменчивости морских берегов мы опирались не на отдельные примеры выявленных по снимкам изменений береговой линии, а на закономерности, изложенные в фундаментальных трудах по геоморфологии морских берегов Г.А. Сафьянова, Г.И. Рычагова, Э. Бёрда, П.А. Каплина и др., вклю- 
чающих и многолетнюю изменчивость береговой зоны. В соответствии с ними основными факторами формирования берегов и их изменчивости являются гидродинамические факторы - различные виды движения воды, и литодинамические факторы, которые включают свойства горных пород, слагающих берег, и различные виды его разрушения (абразии), а также перемещение обломков и осадочного материала потоками воды и их аккумуляцию, формирующие новые участки берега.

В береговой зоне постоянно действует комплекс сил, определяющих ее морфологический облик, линия уреза воды характеризуется непостоянством и меняет свое положение в зависимости от штормовых условий, фазы прилива, давления атмосферы и многих других переменных (Сафьянов, 1996).

В монографии (Бёрд, 1990) на основе подробной характеристики факторов и размеров изменений береговых зон разных регионов автором сделан следующий вывод:

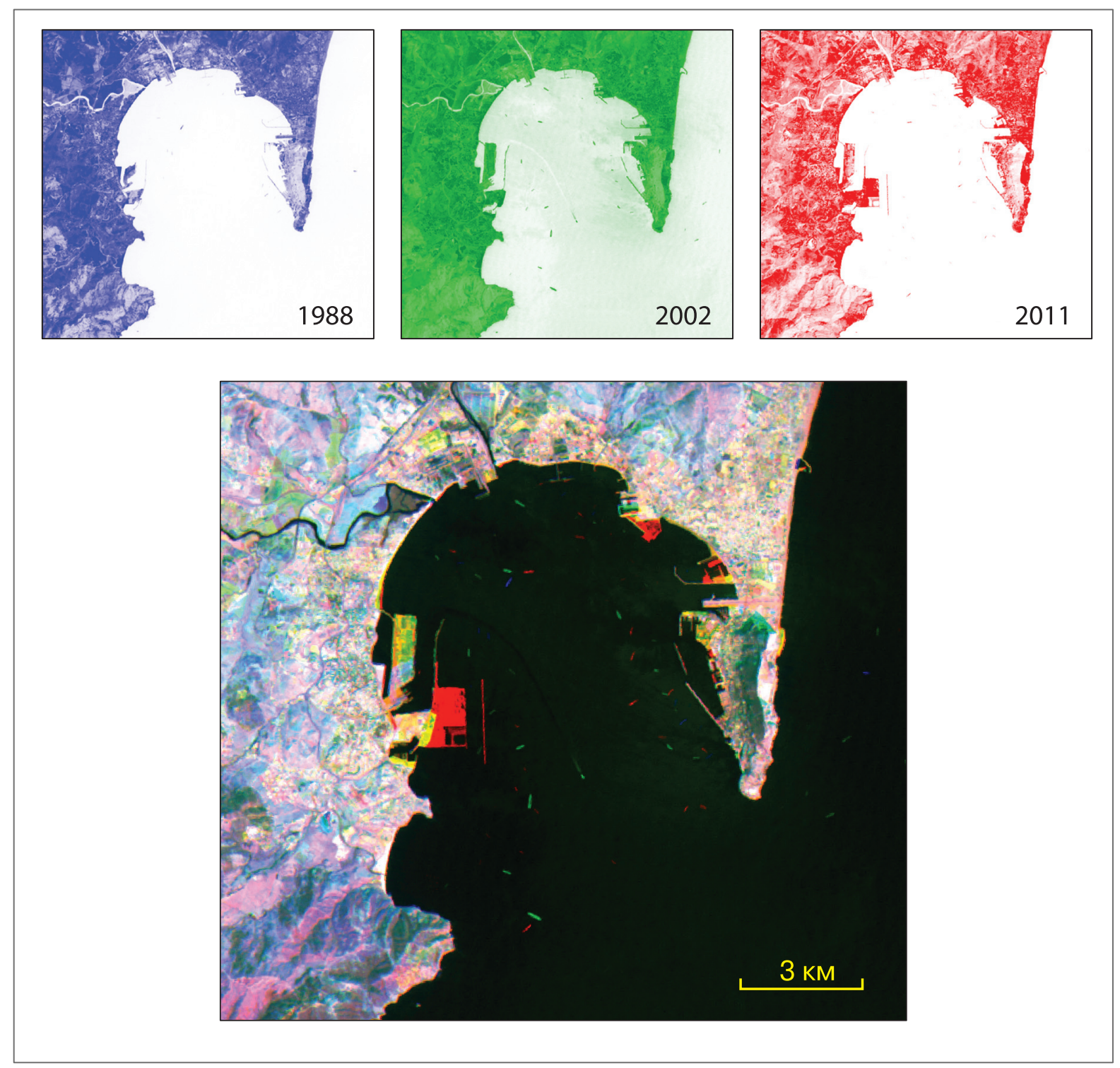

Рис. 2. Техногенные изменения береговой линии в заливе Гибралтар - строительство портовых сооружений. Цветовой синтез разновременных снимков Landsat-5: $R-2011$ г., $G-2002$ г., В - 1988 г., желтый ивет - объекты, построенные к 2002 г., красный - к 2011 г. 
"...Очевидно, что протяженность той части мировой береговой линии, которая за последнее столетие отступила, больше той, которая выдвинулась в море, хотя довольно протяженные участки остались стабильными или выдвижение и отступание были незначительными. Очень мало побережий выдвигалось или отступало со скоростью 100 м в год. Приращение или потеря суши со скоростью 10 м в год в мировом масштабе также считаются исключительными, а берегов, изменявшихся со скоростью более 1 м в год, очень мало" (Бёрд, 1990). Наибольшие изменения могут быть обнаружены на дельтовых берегах, где происходит постоянный вынос наносов. Другие типы меняющихся берегов вулканические, где возможно не только изменение очертаний существующей береговой линии, но и появление значительных массивов суши.

Интенсивно проходит в последнее столетие превращение естественных берегов в искусственные (Бёрд, 1990). Волноотбойные стенки и другие сооружения строятся для того, чтобы остановить размыв берегов. Многие песчаные и галечниковые косы, конфигурация которых ранее менялась, также были искусственно стабилизированы. Многочисленны примеры активного строительства сооружений и расширения зон портов, которые можно выявить по разновременным снимкам со спутников Landsat (puc. 2).

\section{Методы}

Создание карты изменчивости морских берегов для выделенной территории

Сведения, полученные из литературных и картографических источников о типах берегов и характере возможной изменчивости пространственного положения береговой линии, использовались для классификации береговой линии территории исследования. При создании карты вероятной изменчивости береговой линии основным источником информации служила карта типов берегов и преобладающих береговых процессов, приведенная в книге (Каплин и др., 1991). Дополнительными источниками служили разновременные снимки высокого пространственного разрешения, представленные на общедоступных Интернет-порталах. Преимущество имели данные Google Earth, т.к. на этом сервисе не только указана дата съемки, но и имеется возможность проанализировать разновременные снимки высокого разрешения, полученные для некоторых участков в течение последних 10-15 лет, что позволяет оценить, изменяется ли и насколько положение береговой линии в разные сезоны года и в разное время съемки. Использовались также картографические источники, такие как карты приливов и морфологических типов берегов, литологическая и геологическая карты.

Участки береговой линии были классифицированы по степени вероятной изменчивости на три категории (рис. 3):

1 - неизменчивая береговая линия, на участках, сложенных прочными горными породами, вероятная пространственная изменчивость положения линии менее 100 м. 
Как правило, такому типу береговой линии соответствуют берега, сформированные тектоническими процессами и мало измененные морем (первично расчлененные берега);

2 - условно изменчивая береговая линия - вероятная пространственная изменчивость положения линии в пределах от 100 до 500 м. К этой категории отнесены выравнивающиеся берега (абразионно-бухтовые и абразионно-аккумулятивные бухтовые) и берега выровненные;

3 - изменчивая береговая линия - вероятная пространственная изменчивость положения линии более 500 м, представлена преимущественно берегами с приливными или ветровыми осушками, а также эстуариями и дельтами рек.

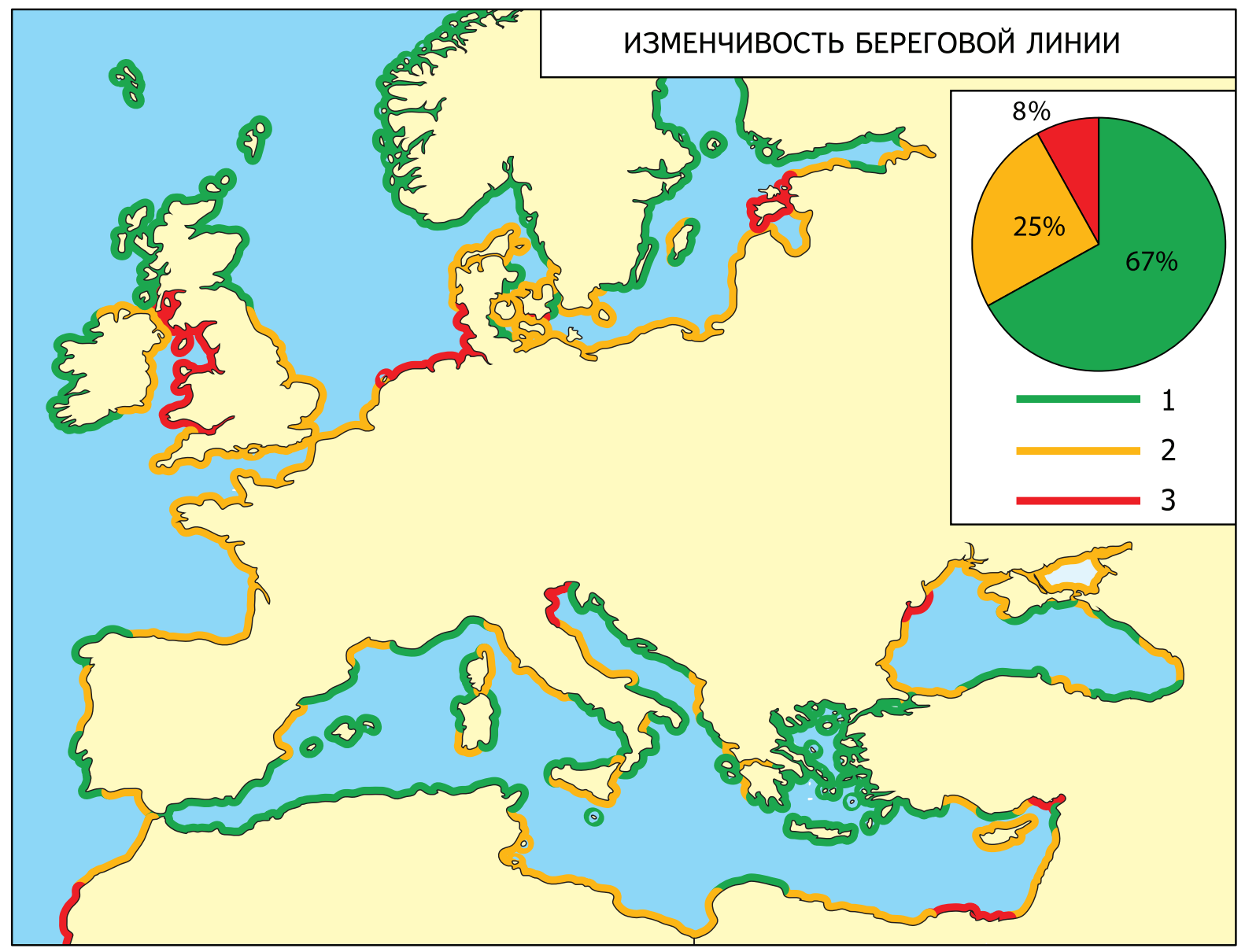

Рис. 3. Изменчивость береговой линии: 1 -неизменчивая; 2 -условно изменчивая; 3 - изменчивая. На диаграмме показано процентное соотномение суммарных длин береговых линий, соответствующих разным классам оценки

Создание карты оценки соответствия береговой линии GSHHG положению, принятому за истинное

Оценка степени соответствия пространственного положения береговой линии карты GSHHG положению береговой линии, принятому за истинное, проводилась для карты уровня детальности “f” путем визуального определения величины расхождения линии 
карты и береговой линии на снимках OLI/Landsat. Для определения этой величины были построены вспомогательные линии, отстоящие от линии карты на 100, 200 и 500 м (puc. 4). Проводилось визуальное дешифрирование положения береговой линии на снимках и определение ее положения относительно линии карты и вспомогательных линий.

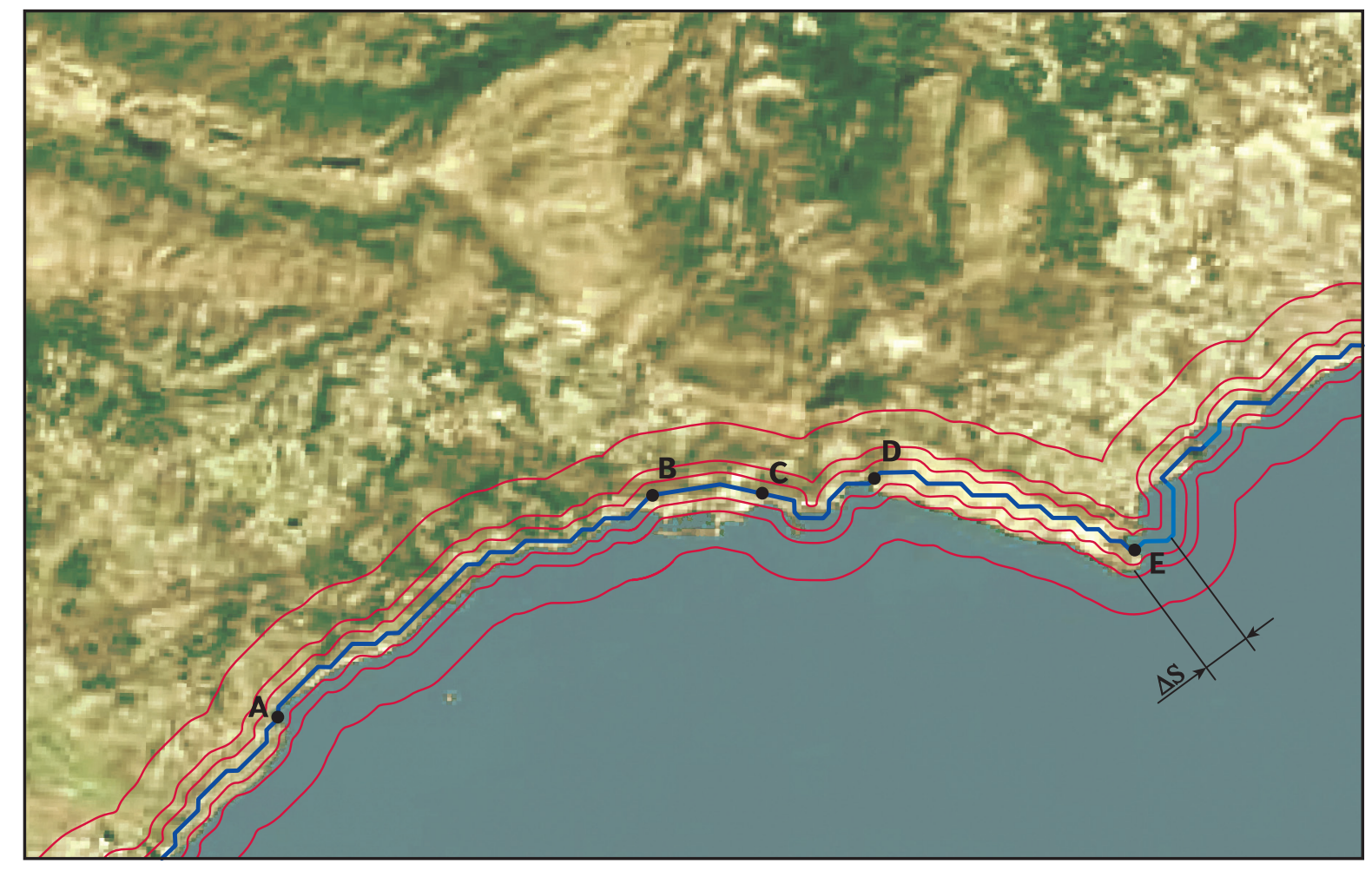

Рис. 4. Фрагмент снимка участка побережья с наложенной береговой линией карты GSHHG уровня детальности "ff" (голубой цвет) и вспомогательные линии (красный ивет) с отстоянием от береговой линии на 100 м, 200 м и 500 м. В приведенном примере отрезки оиениваемой береговой линий попадают в разные категории: $A B$ и CD - отстояние меньше 100 м; $B C-$ искусственный берег-nорт; DE-100-200 м, $\Delta S-$ сдвиг линии, обусловленный неточностью привязки источников карты $G S H H G$

В процессе дешифрирования снимков было выявлено, что для выбранного района исследования характерно наличие значительного числа участков искусственно измененной береговой линии, которые были выделены в отдельную категорию. К ней отнесены территории портов, гаваней и укрепленные (искусственные) берега. На этих территориях береговая линия вследствие антропогенной деятельности является преимущественно стабильной, но при этом на отдельных участках возможны заметные изменения в случае строительства и расширения портовых зон и прочих сооружений.

В отдельную категорию также выделены фрагменты береговой линии с расхождением линии карты и определенного по снимкам ее положения более чем на 500 м, а также заведомо непригодные участки (дельты крупных рек, приливные осушки, некоторые лагуны и косы, шхерные берега и отдельные группы мелких островов).

В результате последовательной визуальной классификации всей береговой линии была создана карта оценки точности положения береговых линий карты GSHHG (для уровня “f”) (рис. 5). 


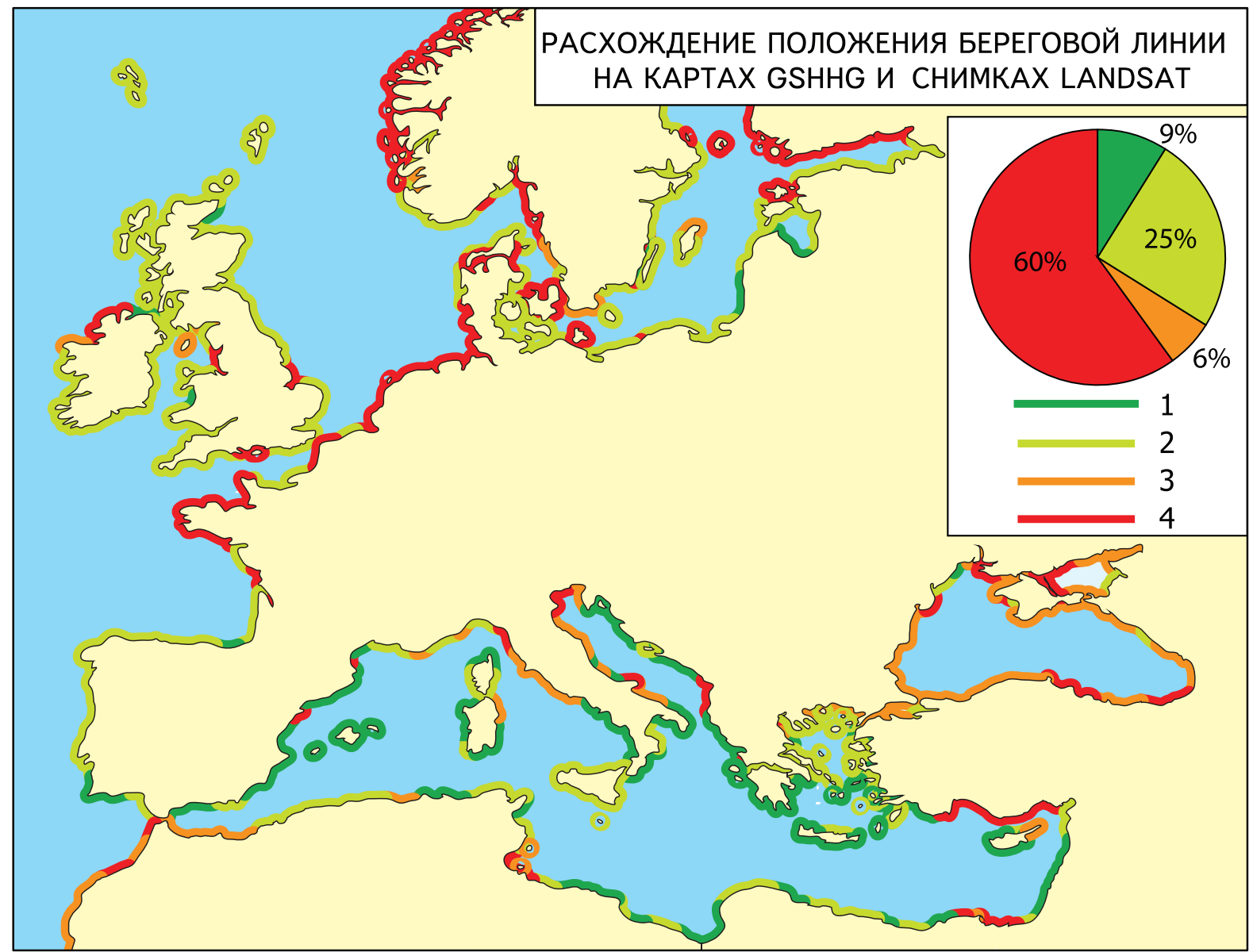

Pис. 5. Оиенка точности изображения береговой линии на карте GSHHG уровня full по величине расхождения с изображением берегов на снимках Landsat: 1 - 0-100 м; 2 - 100-200 м; 3 - 200-500 м; 4 - более 500 м. На диаграмме показано процентное соотношение суммарных длин береговых линий, соответствующих разным классам оценки

\section{Полученные результаты и их анализ}

Результаты проведенной работы представлены в виде следующих карт, составленных на исследуемую территорию:

- карты изменчивости береговой линии, обусловленной природными и антропогенными факторами;

- карты степени расхождения изображения береговой линии GSHHG и ее положения, определяемого по снимкам Landsat.

По результатам классификации береговой линии по степени изменчивости выявлено, что изменчивыми являются около $8 \%$ обследованной линии, условно-изменчивой - $25 \%$, неизменчивой $-67 \%$. Изменчивость оценивалась на основе литературных данных, а для нескольких ключевых участков также путем сопоставления разновременных снимков Landsat, полученных с интервалом 15-20 лет. На снимках отчетливо выявляются лишь изменения, связанные с деятельностью человека по развитию портов, искусственных островов и постройке берегоукрепительных сооружений, доля которых крайне мала относительно общей протяженности обследованной береговой линии. Снимки Landsat оказались малопригодными для выявления и оценки краткосрочных изменений, в первую очередь, приливно- 
отливных, т.к. съемка выполняется в одно и тоже время суток, на которое могут приходиться разные фазы прилива.

Проведена оценка качества картографической базы данных GSHHG по степени ее соответствия требованиям спутниковой навигации. Сравнение результатов оценки точности положения береговой линии базы данных GSHHG и степени изменчивости береговой линии показывает, что основная причина несовпадения линии карты и наблюдаемой на снимках береговой линии мирового океана на обследованной территории - ошибки самой карты, а не произошедшие со времени ее создания изменения береговой линии.

При прослеживании величины расхождения береговой линии GSHHG с ее положением на снимках Landsat выявлено, что лишь 9\% береговой линии отклоняются от «истинного» положения не более, чем на 100 м. В интервал отклонений 100-200 м попадает 25\% береговой линии, а в интервал 200-500 м - 6\%. Непригодной для навигации по причинам, обусловленным точностью карты, признано 60\% обследованной береговой линии, причем половина этого количества приходится на мелкие (площадью менее 10 км²) острова. При этом большая часть береговой линии карты GSHHG правильно отображает ее очертания, а сдвиги относительно ее «истинного» положения свидетельствуют об ошибках в привязке исходных материалов к единой системе координат при создании карты.

Проведенные исследования по оценке пространственного положения береговой линии картографической базы данных GSHHG позволяют предположить, что принятый при составлении GSHHG подход к выбору источников и принципов составления, нацеленный на создание карты для использования в геоинформационных системах, ограничивает пригодность этой карты в предполагаемых системах космической навигации.

\section{Выводы}

Результаты проведенных исследований показывают, что, хотя около 67\% протяженности береговой линии Европы и северной Африки можно считать неизменной и потому потенциально пригодной для космической навигации, лишь 9\% длины береговой линии карты GSHHG имеют точность не хуже 100 м, 34\% - не хуже 200 м, и 40\% - не хуже 500 м. Отсюда следует, что при использовании для космической навигации карт GSHHG:

- для навигации необходимо выбирать участки береговой линии, представленные на карте с необходимой точностью,

- нет необходимости выбирать пространственное разрешение навигационных камер лучше 100-200 м.

Необходима критическая ревизия базы данных GSHHG для того, чтобы полностью использовать потенциал космической оптической навигации по неизменным участкам береговой линии. Для этого целесообразно составление специальной карты береговых линий на основе использования космических снимков и применения принципов их генерализации, сходных с принципами построения изображения оптическими системами. 


\title{
Литература
}

1. Аванесов Г.А., Бессонов Р.В., Форш А.А., Куделин М.И. Анализ современного состояния и перспектив развития приборов звездной ориентации семейства БОКЗ // Сборник трудов 4-й Всероссийской научнотехнической конференции "Современные проблемы ориентации и навигации космических аппаратов". Россия. Таруса, 8-11 сентября 2014 г. М.: ИКИ РАН, 2015. С. 6-20.

2. Бёрд Э.Ч.Ф. Изменения береговой линии: Глобальный обзор. Л.: Гидрометеоиздат, 1990. 255 с.

3. Гришин B.A. Повышение точности навигации космических аппаратов при использовании глобальной карты береговых линий // Техническое зрение. 2014. Вып. 1. С. 44-52.

4. Егошкин Н.А., Еремеев В.В., Козлов Е.П., Москатиньев И.В., Москвитин А.Э. Геодезическая привязка изображений от геостационарных спутников по контуру диска Земли и электронным картам // Современные проблемы дистанционного зондирования Земли из космоса. 2009. Вып. 6. Т. 1. С. 132-138.

5. Жуков Б.С., Жуков С.Б., Фори А.А. Возможности навигационных измерений по лимбу Земли в видимом и ближнем ИК диапазоне // Современные проблемы дистанционного зондирования Земли из космоса. 2015. T.12. № 2. С. 61-76.

6. Каплин П.А., Леонтьев О.К., Лукьянова С.А., Никифоров Л.Г. Берега. М: Мысль, 1991. 479 с.

7. Сафьянов Г.А. Геоморфология морских берегов. 1996. 400 с.

8. NOAA Shoreline Website: http://www.ngdc.noaa.gov/mgg/shorelines/.

9. Spaulding B.C. Automatic satellite image navigation. Naval Postgraduate School, Monterey, California. 1990.83 p. (http://hdl.handle.net/10945/34940).

10. USGS. Landsat 8 (L8) Data Users Handbook, LSDS-1574, version 1.0. Sioux Falls, USA: USGS EROS, 2015. 98 p. (https://landsat.usgs.gov/documents/Landsat8DataUsersHandbook.pdf).

11. Wessel P., Smith W.H.F. A Global Self-consistent, Hierarchical, High-resolution Shoreline Database // J. Geophys. Res. 1996. Vol. 101. P. 8741-8743.

\section{Suitability estimation of GSHHG coast line map for autonomous optical spacecraft navigation}

\author{
E.A. Baldina1, R.V. Bessonov², V.A. Grishin ${ }^{2}$, B.S. Zhukov², E.G. Kharkovets ${ }^{1}$ \\ ${ }^{1}$ Moscow State University, Moscow 119991, Russia \\ E-mail: baldinaea@yandex.ru \\ ${ }^{2}$ Space Research Institute RAS, Moscow 117997, Russia \\ E-mail: besson777@rambler.ru
}

Temporal variability of Europe and North Africa coast line and the accuracy of its spatial location in GSHHG (Global Self-consistent, Hierarchical, High-resolution Geography Database) map were analyzed for the purpose of sensor and algorithm development for autonomous optical spacecraft navigation. A map of the coast line potential long-term variability was developed based on analysis of the literature on the coast zone of the world ocean and its specific features for the study area. The GSHHG coast line accuracy was estimated by its comparison with OLI/Landsat-8 images acquired in 2013-2015 that were used as a reference. This resulted in a GSHHG accuracy map. The results allow a quantitative estimation of the GSHHG suitability for navigation purposes. It was found that only $8 \%$ of the analyzed coast line is highly variable and unsuitable for navigation, while $67 \%$ of the coast line is stable and potentially suitable. However, only $9 \%$ of the GSHHG coast line deviates from its reference location by less than $100 \mathrm{~m}$, while the deviation of $34 \%$ and $40 \%$ of the GSHHG coast line is less than 200 and $500 \mathrm{~m}$, respectively. This implies the necessity for a critical revision of GSHHG maps to fully utilize the potential of spaceborne autonomous optical navigation using the stable coast line sections.

Keywords: coastline variability, GSHHG accuracy, autonomous optical spacecraft navigation 


\section{References}

1. Avanesov G.A, Bessonov R.V., Forsh A.A., Kudelin M.I. Analiz sovremennogo sostoyaniya i perspektiv razvitiya priborov zvezdnoi orientatsii semeistva BOKZ (Analysis of current state and development prospects of star trackers of BOKZ family), Proc, 4th all-Russia Conf. "Sovremennye problemy orientacii i navigacii kosmicheskih apparatov", Tarusa, 8-11 September 2014, Moscow: IKI RAN, 2015, pp. 6-20.

2. Bird E.C.F. Izmeneniya beregovoi linii: Global'nyi obzor (Coastline changes. A global review), Leningrad: Hydrometeoizdat, 1990, 255 p.

3. Grishin V.A. Povyshenie tochnosti navigatsii kosmicheskikh apparatov pri ispol'zovanii global'noi karty beregovykh linii (Improving spacecraft navigation accuracy using a global coastlines map), Tehnicheskoe zrenie, 2014, Vol. 1, p. 44-52.

4. Egoshkin N.A., Eremeev V.V., Kozlov E.P., Moskatin'ev I.V., Moskvitin A.E. Geodezicheskaya privyazka izobrazhenii ot geostatsionarnykh sputnikov po konturu diska Zemli i elektronnym kartam (Geodetic binding of images from the geostationary satellite on a contour of a disk of the Earth and electronic maps), Sovremennye problemy distantsionnogo zondirovaniya Zemli iz kosmosa, 2009, Issue 6, Vol. 1, pp. 132-138.

5. Zhukov B.S., Zhukov S.B., Forsh A.A. Vozmozhnosti navigatsionnykh izmerenii po limbu Zemli v vidimom i blizhnem IK diapazone (Potential of Earth limb navigation measurements in the visible and near-IR spectral range), Sovremennye problemy distantsionnogo zondirovaniya Zemli iz kosmosa, 2015, Vol. 12, No. 2, p. 61-76.

6. Kaplin P.A., Leont'ev O.K., Luk'yanova S.A., Nikiforov L.G. Berega (Seashores), Moscow: Mysl', 1991,479 p.

7. Saf'yanov G.A. Geomorfologiya morskikh beregov (Coastal geomorphology), Moscow: MSU, 1996, 400 p.

8. http://www.ngdc.noaa.gov/mgg/shorelines/.

9. Spaulding B.C. Automatic satellite image navigation, Naval Postgraduate School, Monterey, California, 1990, 83 p., http://hdl.handle.net/10945/34940.

10. USGS. Landsat 8 (L8) Data Users Handbook, LSDS-1574, version 1.0, Sioux Falls, USA: USGS EROS, 2015, 98 p. (https://landsat.usgs.gov/documents/Landsat8DataUsersHandbook.pdf).

11. Wessel P., Smith W.H.F. A Global Self-consistent, Hierarchical, High-resolution Shoreline Database, J. Geophys. Res., 1996, Vol. 101, pp. 8741-8743. 